\title{
"Siempre tienen a los pobres entre ustedes" (Jn 12, 8): la opción por los pobres: límites y desafíos para hoy"
}

\author{
Roberto Caicedo Narváez
}

Recepción: 27 de agosto de 2018 • Aprobación: 29 de septiembre de 2018

\section{Resumen}

Regularmente el pasaje de Jn 12, 8 se usa para justificar la presencia de los pobres en el contexto social, como si fuese una condición necesaria, como algo inevitable, natural y divino. La Conferencia de Medellín puso en el tapete de la discusión teológica y pastoral la realidad de la pobreza como una situación antievangélica. Las implicaciones de este desafío marcaron el impulso por acompañar las reivindicaciones de los sujetos sociales en sus aspiraciones por los cambios políticos en América Latina que dieran al traste con las condiciones de marginalidad económica y social, y así ampliaron el espectro de su compromiso. Hoy nos encontramos con un continente que sigue buscando salidas a estas condiciones estructurales y culturales que no permiten el tan anhelado cambio, pues aún seguimos "teniendo" a los pobres en medio nuestro, y algunos no nos resignamos a aceptarlo como un designio divino o histórico. Es necesaria una relectura que nos acerque al texto bíblico con otros ojos para entender mejor el desafío de Jesús hoy. Son estas las inquietudes que pretendemos discutir en este artículo, cincuenta años después del llamado de Medellín a escuchar el clamor de los pobres.

Palabras clave: compromiso de las iglesias, exclusión social, opción por los pobres, relectura de la biblia.

Artículo de reflexión preparado para el Primer Congreso Internacional de Teología Latinoamericana y del Caribe: 50 años de Medellín: Iglesia y signos de los tiempos, desarrollado en la Universidad Santo Tomás entre el 16 y el 19 de octubre de 2018. Citar como: Caicedo Narváez, R. (2018). "Siempre tienen a los pobres entre ustedes" (Jn 12, 8): la opción por los pobres: límites y desafíos para hoy. Albertus Magnus, IX(2), 119-141. Doi: https://doi.org/10.153322/5005413.4977.

* Fundación Universitaria Bautista, Colombia. Orcid: https://orcid.org/0000-0001-90356171. Correo electrónico: rcaicedo@unibautista.edu.co 


\title{
"You will always have the poor among you" (John 12, 8): The option for the poor: limits and challenges for today
}

\begin{abstract}
Regularly, the passage of John 12, 8 is used to justify the presence of the poor in the social context, as if it were a necessary condition, as something inevitable, natural and divine. The Medellín Conference brought forward in the theological and pastoral discussion the reality of poverty as an antievangelical situation. The implications of this challenge marked the impulse to accompany the demands of the social subjects in their aspirations for the political changes in Latin America that would end the conditions of economic and social marginalization, thus expanding the spectrum of their commitment. Today we find a continent that continues to look for ways out of these structural and cultural conditions that do not allow for the much desired change, because we still "have" the poor in our midst, and some do not resign ourselves to accept it as a divine or historical design. It is necessary a rereading that brings us closer to the biblical text with different eyes to better understand the challenge of Jesus today. These are the concerns that we intend to discuss in this paper, fifty years after the Medellin call to listen to the cry of the poor.
\end{abstract}

Keywords: commitment of the churches, social exclusion, option for the poor, rereading the Bible.

\section{"Eles sempre têm os pobres entre vocês" (Jo 12, 8): a opção pelos pobres: limites e desafios para hoje}

\section{Resumo}

Regularmente a passagem de João 12, 8 é usado para justificar a presença dos pobres no contexto social, como se fosse uma condição necessária, como algo inevitável, natural e divino. A Conferência de Medellín colocou a realidade da pobreza como uma situação antievangélica na mesa da discussão teológica e pastoral. As implicações desse desafio marcaram o impulso de acompanhar as demandas dos sujeitos sociais em suas aspirações pelas mudanças políticas em América Latina. isso terminaria as condições de marginalização econômica e social, ampliando assim o espectro de seu compromisso. Hoje temos um continente que continua a procurar soluções para essas condições estruturais e culturais que não permitem a mudança tão esperada, porque ainda "tem" a pobres em nosso meio, e alguns que não se resignam a aceitar como um design divino ou histórico. É necessária 
uma releitura que nos aproxime do texto bíblico com olhos diferentes para entender melhor o desafio de Jesus hoje. Essas são as preocupações que pretendemos discutir neste artigo, cinquenta anos depois do chamado de Medellín para ouvir o clamor dos pobres.

Palavras-chave: compromisso das igrejas, exclusão social, opção pelos pobres, releitura da bíblia.

\section{Introducción}

Hace cincuenta años la II Conferencia Episcopal Latinoamericana, realizada en Medellín, puso en el tapete de la discusión teológica y pastoral la realidad de la pobreza como una situación antievangélica: “El Episcopado Latinoamericano no puede quedar indiferente ante las tremendas injusticias sociales existentes en América Latina, que mantienen a la mayoría de nuestros pueblos en una dolorosa pobreza cercana en muchísimos casos a la inhumana miseria" (Consejo Episcopal Latinoamericano [Celam], 1989, p. 103). El llamado a una "opción por los pobres", aunque en el texto final del Celam no se usó propiamente el término, empezó a hacer carrera dentro de movimientos conectados por la teología de la liberación en nuestro continente, tanto en su vertiente católica como protestante, que animaron a las comunidades a un compromiso por la superación de esas condiciones de injusticia y llamaron a la Iglesia institucional a ser ejemplo de una vida solidaria con los pobres y a una opción sociopolítica para superar las condiciones que la producían.

En esta misma línea, dos de sus representantes se planteaban años después: En la medida en que la opción por los pobres toca la cuestión de las clases, nos preguntamos cómo queda la catolicidad de la Iglesia en cuanto abierta a todos [...] ¿Es la opción por los pobres una opción de clase? [...] ¿Supone la opción por los pobres una lucha de clase? (Pixley y Boff, 1986, p. 143)

De tal forma que, para la apuesta de la teología de la liberación, en su momento marcó el impulso para acompañar las reivindicaciones de diversos sujetos sociales en sus aspiraciones por los cambios políticos y económicos en América Latina, que dieran al traste con las condiciones de marginalidad económica y social, y así ampliar el espectro de este compromiso a las diferentes formas de marginalización y exclusión en el continente.

Hoy nos encontramos con un continente que sigue buscando salidas a estas condiciones estructurales y culturales que no permiten ver realizados los anhelados cambios, por lo menos no para un sector de la población. Hemos pasado por 
diferentes esfuerzos sociales, políticos e ideológicos, hemos ampliado la discusión teológica y pastoral sobre el compromiso de las Iglesias en la transformación social, cultural y política de nuestros países, pero aún seguimos "contando" con los pobres en medio nuestro, y algunos no nos resignamos a aceptarlo como un designio divino o histórico, como puede sugerir una lectura "ingenua" del texto bíblico referenciado en el título de este artículo.

¿Qué queda de ese llamado de Medellín para hoy? ¿Cómo podemos asumirlo ante los alcances y las frustraciones de nuestro devenir social y político en nuestro país y continente? ¿Podemos encontrar en ese compromiso una fuente de alianza ecuménica desde las diferentes Iglesias? ¿Es necesaria una relectura de la Biblia, con una perspectiva diferente, para acercarnos a textos como el de Juan, para entender el modelo y llamado de Jesús para con los pobres? Son estas las inquietudes que pretendemos discutir en este artículo, cincuenta años después del llamado de Medellín a escuchar el clamor de los pobres de América Latina.

\section{1. ¿De qué hablamos cuando decimos pobreza?}

Como otros términos, el de pobreza es un vocablo multívoco, es decir, tiene varias connotaciones y posibilidades de interpretación. La primera forma de entenderlo tiene que ver con los aspectos económicos y las posibilidades de una persona de acceder a una serie de condiciones básicas que le permiten, por lo menos, subsistir. Pero en otras referencias puede relacionarse con carencias de todo tipo, inclusive de tipo emocional o espiritual; quien carece de algo se considera pobre en esa dimensión en la cual hay carencia. Así pues, pobreza llega a ser un término usado en aspectos inclusive contrarios, como la frase "Alguien es tan pobre que solo posee dinero".

También en el contexto de la Celam de Medellín la pobreza se plantea en diferentes formas. En un primer sentido, se refiere a "condiciones objetivas" de los pueblos a causa de políticas de marginalización sujetos a la dependencia económica de los Estados frente a intereses trasnacionales. Así entonces se comenta:

Recordemos, una vez más, las características del momento actual de nuestros pueblos en el orden social: desde el punto de vista objetivo, una situación de subdesarrollo, delatada por fenómenos masivos de marginalidad, alienación y pobreza, y condicionada, en última instancia, por estructuras de dependencia económica, política y cultural con respecto a las metrópolis industrializadas que detentan el monopolio de la tecnología y de la ciencia (neocolonialismo). (Celam, 1989, p. 48) 
Desde esta perspectiva, la pobreza es resultado de la injusticia social y la inequidad económica que lleva a vivir en condiciones de pobreza a buena parte de la sociedad, posiblemente hoy menos que hace cincuenta años, si nos atenemos a las estadísticas oficiales. ${ }^{1}$ Sin embargo, las estadísticas muestran datos preocupantes en cuanto a la concentración de la riqueza en Colombia, pues el índice Gini sigue sin sufrir un cambio significativo en el tiempo, al igual que el porcentaje de subalimentación de la población. Aunque las características en la forma de medir la pobreza han cambiado, en 2002 el Departamento Administrativo Nacional de Estadística (DANE) varía la forma de valorar la condición de pobreza, supuestamente para integrar nuevos factores antes no considerados. Pero también las causas de la pobreza se han ido modificando, sobre todo por el agudizamiento del conflicto armado, que afectan las condiciones de empobrecimiento de ciertos sectores de la población colombiana que permanecen y que se van agravando con el tiempo, como sectores campesinos, grupos indígenas y comunidades de afrodescendientes principalmente rurales o en las periferias de las grandes ciudades. La cuestión aquí es ¿dónde se han concentrado la condiciones de pobreza en nuestro país, en el continente, y por qué razones se da esa concentración y su permanencia en el tiempo? ¿Cómo ha afectado las condiciones de pobreza la victimización por el conflicto? Estas preguntas sustanciales están por fuera de los informes oficiales. Se citan aquí como ejemplo los informes de la Comisión Económica para América Latina y el Caribe (Cepal). A comienzos de este siglo se señala:

El incremento de la pobreza entre 1995 y 2000 se ha debido totalmente al incremento en el desempleo; de no ser por el incremento en el nivel de la educación de los hogares y la reducción en el tamaño del hogar, la situación hubiera sido más crítica: un aumento de $10 \%$ en el nivel educativo de los hogares reduce la pobreza total en $9 \%$; un aumento de la tasa de ocupación de $10 \%$, reduce la pobreza $30 \%$. El mayor nivel de pobreza aparece relacionado positivamente con los incrementos en

1 Las estadísticas de la Cepal muestran que el coeficiente de la brecha de pobreza (Banco Mundial) medido a partir de las personas que viven con menos de USD 3,1 al día pasó en 1988 de 9,1 a 5,0 en 2014, lo cual implicaría un cierto mejoramiento en el nivel de la adquisición monetaria de las personas. Sin embargo, la misma Cepal muestra que la prevalencia de la subalimentación en la población (porcentaje) pasó, a comienzos de la década de 1990, de 9,7 a 7,1, a fines de 2016. Igualmente, el índice Gini, que mide la concentración de ingresos, pasó, de 0,531 a comienzos de la década de 1990, a 0,535 en 2014, lo que muestra un cambio mínimo en este aspecto. Sin embargo, aclara la Cepal, la estadística ha sufrido un cambio metodológico a partir de 2002 en la forma en la que son medidos por parte del DANE. 
el desempleo y la inflación, y con la mayor regresividad en la distribución del ingreso; incrementos en la tasa de cambio real y en el salario mínimo real disminuyen la pobreza. En 15 años se podría reducir la pobreza a la mitad, si el PIB per cápita aumenta a un nivel promedio del $4 \%$ anual y si, al mismo tiempo, la distribución del ingreso mejora en promedio 0.5 \% por año. (Núñez y Ramírez, 2002, p. 5)

Tal presentación de la realidad de la pobreza la ve como un fenómeno netamente económico dejando por fuera otros factores sustanciales, como los que se han señalado: históricos, étnicos y conflictuales. La cuestión no ha mejorado sustancialmente, aunque en los nuevos modelos de medición se han incluido indicadores de tipo no económicos, como la salud, la educación y la calidad del hábitat. Pero, al desmenuzar estos indicadores, siguen estando por fuera cuestiones clave, como la victimización y la discriminación histórica (cf. Villatoro, 2017, p. 18). El expresidente colombiano Juan Manuel Santos, en uno de sus discursos, reconoció la necesidad de hacer cambios en estas formas de "medir" la pobreza:

Cambiamos la forma de medir la pobreza. Nos inspiramos en el Premio Nobel de Economía, Amartya Sen, de la India. Él decía, fue profesor mío hace muchos años: esa forma tan material de medir la pobreza simplemente por ingresos, no era la forma apropiada. Que había una forma más humana y más efectiva de medir y luchar contra la pobreza. Lo llamó la "pobreza multidimensional", que no mide la pobreza por ingresos, sino mide la pobreza por qué tiene una persona o una familia en su vida... Y si uno mide esas necesidades básicas así podrá medir mejor y combatir mejor la pobreza. Pues bien, hoy en América Latina, nos da mucho orgullo decirlo, somos el país que más ha logrado bajar la pobreza. Hemos reducido la pobreza extrema en solo 7 años a la mitad y hemos sido el país que más ha logrado cerrar las brechas de las desigualdades... Y creo que los resultados están a la vista. ("Palabras del Presidente Juan Manuel Santos en el foro del Consejo Mundial de Iglesias", 2018)

Por otro lado, hay que también indicar que el término pobreza se usó en la Celam para hablar de una opción por una vida sencilla, siguiendo el modelo de Jesús, sin la acumulación de riquezas, y que es deseable para que la Iglesia, en el sentido institucional y vocacional, pueda ser testimonio del mensaje de Jesús a la sociedad y también solidarizarse con quienes están en la pobreza económica. 
Una de las características indispensables de la espiritualidad sacerdotal, especialmente requeridas por nuestra situación continental, es la pobreza evangélica. La pobreza evangélica, que es vivida en la Iglesia de acuerdo con distintas vocaciones, tendrá que concretarse, para los presbíteros diocesanos, en un estilo de vida que les dé las posibilidades económicas que se adecuen a un ministerio de especial situación comunitaria. (Celam, 1989, pp. 55-56)

Pero esta condición de pobreza, a diferencia de la anterior, es una opción, la otra es una imposición no deseable para quienes la viven. Pero se puede preguntar si acaso no será una condición propia, deseable y hasta necesaria para sostener el desarrollo de los sistemas sociales y económicos en los cuales hasta ahora nos hemos movido como sociedad. Es decir, la cuestión es si la conformación de nuestros sistemas sociales lleva en su génesis la condición de la pobreza de un sector de la población. Cuestión difícil de responder y a la cual nos podríamos acercar en forma inductiva, es decir, a partir de las condiciones propias de cada sistema social en particular para determinar si tal premisa se cumple en alguna medida o en una forma deductiva planteando la generalización de un sistema social a partir de sus presupuestos ideológicos y ver en la práctica cómo se concreta en diversos sistemas particulares que generan o no condiciones de pobreza. Cualquiera de las dos vías es, pues, compleja y requeriría una investigación amplia, las cuales de seguro ya encontramos en la bibliografía sobre el tema.

Podríamos, entonces, renunciar al esfuerzo o intentar desde una perspectiva más bien heurística, proponiendo una categoría que nos permita escudriñar en un sistema social y económico, tanto en su nivel ideológico y general como a nivel particular y pragmático, si genera o permite que parte de su población viva en condiciones que podamos llamar de pobreza, en ese determinado sistema, y que pueda ser incluso modificada de acuerdo con los cambios que dicho sistema vaya sufriendo en la historia. La cuestión es la siguiente: ¿cómo podemos entender la pobreza como una categoría de análisis interpretativo de una situación social en particular?

Proponemos, entonces, lo siguiente: la pobreza es ante todo una forma de victimización social que se justifica en la medida en que permite el bienestar de una parte de una sociedad a expensas de la otra. Esta justificación puede ir, desde una forma explícita en la que se considera abiertamente la necesidad de empobrecer a otros, a una forma implícita en la que se soporta, se relativiza o se oculta la condición de pobreza de algunos por parte de otros. Seguramente aquí no hay algo nuevo; ya se ha expresado en diversas esferas la pobreza como 
victimización. La cuestión es si esta mirada nos ayuda a entender mejor las demandas para nuestra acción y compromiso cristiano; si nos ayuda en una relectura del texto bíblico y salvar las diferencias sociales entre el mundo del Nuevo Testamento y el nuestro.

Ver al pobre como una víctima social permite en consecuencia entender que, a pesar de las diferencias concretas en que esta pobreza se viva o se mida, en términos económicos, tal condición de víctima puede señalarnos que hay cosas en común entre un pobre en el siglo I y un pobre en el contexto actual. El Celam lo planteó en términos más teológicos: la pobreza es un mal social y resultado del pecado de los seres humanos. En sus términos: "La pobreza como carencia de los bienes de este mundo es, en cuanto tal, un mal. Los profetas la denuncian como contraria a la voluntad del Señor y las más de las veces como el fruto de la injusticia y el pecado de los hombres"' (Celam, 1989, p. 67).

Un corolario de lo anterior o una implicación es por tanto que la promoción, provocación o indiferencia ante la condición de pobreza de un sector de la sociedad es una forma de violencia. Ya algunos la han llamado violencia estructural. ${ }^{2}$ En Colombia, específicamente, esa violencia se ha unido a la violencia armada para terminar cumpliendo su cometido en forma más certera: el empobrecimiento de las comunidades más vulnerables. Por ejemplo, el caso de la Costa Pacífica, donde las comunidades de Buenaventura en el pasado movimiento se plantearon como "víctimas del modelo económico". ${ }^{3}$

En este sentido, es claro, aunque no para todos, que el conflicto en Colombia es la herencia de un conflicto no resuelto de medio siglo atrás, que desde el punto de vista de los estudios poscoloniales sería la historia de la "colonialidad del poder" que nos ha caracterizado, como bien lo constata Quijano (2000):

Hoy, la lucha contra la explotación/dominación implica sin duda, en primer término, la lucha por la destrucción de la colonialidad del poder, no solo para terminar con el racismo, sino por su condición de eje articulador del patrón universal del capitalismo eurocentrado. Esa

2 Por ejemplo, "para Kalmanovitz [...] en su análisis estructural, la violencia se manifiesta como consecuencia del atraso cultural y la formación cotidiana de una mentalidad del crimen, auspiciada por los aparatos ideológicos de Estado como la prensa y la televisión; al igual, que la falta de oportunidades y los bajos niveles de participación de la sociedad civil en las decisiones económicas y políticas del país" (Velásquez, 2014, p. 215).

3 Así se plantea su reclamo: “La militarización de la región y la agresión oficial a la población reproducen el terror instaurado por los grupos al margen de la ley durante las tres últimas décadas. ¿Es esta la respuesta de un nobel de paz a 'sus compatriotas'? ¿Estamos frente a la continuidad de un modelo económico que se mantiene a través de la guerra?" (Arboleda, 2017). 
lucha es parte de la destrucción del poder capitalista, por ser hoy la trama viva de todas las formas históricas de explotación, dominación, discriminación, materiales e intersubjetivas. (p. 380)

Aunque los actores hayan cambiado y las mutaciones propias del correr de la historia se hagan presentes, seguimos manteniendo patrones de poder colonial en nuestro conflicto. Algunas experiencias en Colombia así lo han demostrado. Se trae a colación, someramente, el caso de la comunidad de Las Pavas en el Magdalena Medio en Colombia. Se puede constatar que el desplazamiento de la comunidad de Las Pavas obedece a propósitos de terratenientes de la zona que desean invertir en la siembra de palma africana, macroproyecto que tiene el impulso desde tiempo atrás del Gobierno y que han usado a grupos paramilitares para expulsar de sus tierras a comunidades campesinas, como el caso mencionado. No es difícil constatar que el conflicto en Colombia ha tenido y mantiene causas de tipo económico, intereses económicos nacionales e internacionales y por ende intereses neocolonizadores, en los que se han visto involucrados gremios económicos de nuestro país y multinacionales.

En Colombia, ha sido frecuente responder con violencia a las luchas y a los reclamos de los pueblos indígenas, afro y campesinos por permanecer en sus tierras y oponerse a la implementación de megaproyectos internacionales. Ejemplo de ello es la resistencia de los indígenas embera-katío contra la represa de Urrá y los u'wa contra la explotación petrolera que han marcado la pauta de esta resistencia. A finales del siglo pasado, uno de sus voceros decía al respecto:

Nuestra posición y filosofía es NO a la penetración de la Oxy. Nuestro territorio es sagrado. La tierra es vida para nosotros. El problema del petróleo es problema de todos los colombianos. Nuestros padres y nuestras autoridades nos han dejado esas tierras para cuidarlas. NO queremos ver nuestras lagunas y nuestros ríos contaminados porque son nuestra vida. Estamos pidiendo la restitución de nuestro territorio. Pedimos su solidaridad. (Encuentro Nacional de Organizaciones Sindicales, 1997, p. 13)

Esta lucha persiste hoy; a pesar de los esfuerzos en darle un cambio a esta política de Estado, las comunidades involucradas siguen experimentando muchas dificultades y el acoso de diferentes estamentos y grupos de poder para imponer sus proyectos, legales o ilegales. Con un agravante, que no es del todo nuevo, el asesinato de líderes que se oponen a esos intereses, fenómeno que, después del acuerdo de desmovilización de las Fuerzas Armadas Revolucionarias de 
Colombia (FARC), se ha incrementado y se ha dejado ver como parte ya de una vieja estrategia, la expropiación violenta de los recursos naturales y de la tierra en nuestro país a costa de la vida de las comunidades más vulnerables y por ende empobrecidas.

En realidad, lo que encontramos es que se utilizó como pretexto la situación de conflicto armado para instrumentar una intervención económica que aseguró la entrada en vigencia de las políticas neoliberales enmarcadas en acuerdos bilaterales, como los tratados de libre comercio (TLC), y en contra de las luchas pacíficas de los pueblos indígenas, afro y campesinos por sus territorios y las condiciones mínimas para una vida digna. La liberalización de la economía y la apertura a las importaciones, bajo el mandato de los acuerdos de la Organización Mundial de Comercio (OMC), ha causado la decadencia de la agricultura colombiana, hasta el punto de que el área sembrada en cultivos legales se redujo en más de un millón de hectáreas y las importaciones de alimentos aumentaron un 700 \% en los últimos veinte años (Mondragón, 2003). En este sentido, se planteó que la usurpación de la propiedad colectiva en territorios protegidos de las cuencas del Curvaradó y Jiguamiandó, en el Chocó, tuvo todos los ingredientes que están detrás de este modelo: presión de grupos paramilitares (ahora llamadas bandas criminales-BACRIM), presencia de empresarios ambiciosos y el apoyo institucional de sectores del Estado que legitiman el despojo y la creación de grandes proyectos productivos asociados a la siembra de palma de aceite. (Verdad Abierta, 2011)

En resumen, estos son algunos de los "valores" propios de una sociedad victimizadora. Así los resume Hinkelammert (2011):

Los valores que se cumplen son en especial los siguientes: la competitividad, la eficiencia, la racionalización y funcionalización de los procesos institucionales y técnicos y en general los valores de la ética del mercado. Los podemos sintetizar en el valor central del cálculo de la utilidad propia, sea de parte de los individuos y de las colectividades que se comportan y que calculan como individuos, como son los Estados, las agrupaciones de Estados, instituciones incluyendo las empresas y organizaciones. Son para el efecto de su cálculo de la utilidad propia individuos colectivos. (p. 1)

En esta lógica, lo que es realmente indispensable es "inútil", pues no obedece al cumplimiento de estos "valores fundamentales"; no es útil para alcanzarlos, por tanto, sobra, estorba y es aniquilado. La naturaleza es inútil a no ser que sea 
transformada en capital natural para explotarla calculando la utilidad propia. El ser humano es inútil y hasta "desechable" a no ser que sea transformado en capital humano por explotar en función de su utilidad propia, sea la utilidad propia del mismo ser humano que se considera capital humano a sí mismo o por otros que lo quieren explotar en función de sus respectivas utilidades propias. "Siempre lo indispensable - el ser humano en cuanto humano y la naturaleza externa en cuanto naturaleza - es inútil" (Hinkelammert, 2011, p. 3). Se genera así un principio de "sacrificialidad" en la sociedad, fundamentado en un modelo económico centrado en el mercado y adecuado para el discurso propio de la modernidad. Este principio genera "víctimas reales" y concretas, tanto seres humanos como en la naturaleza que le rodea. Al respecto, afirma Dussel (1998):

El mercado que pareciera operar performativamente de manera autorregulada no es sino la compleja estructura cooperativa del cumplimiento de reglas [...] de sujetos concretos vivientes [...] Pero el sujeto aparece en toda su claridad en las crisis de los sistemas [...] Surge así en y ante los sistemas [...] por dichas situaciones críticas, el Otro [...] el rostro del oprimido o excluido, la víctima no intencional como efecto de la lógica performativa del todo formal racionalizado, mostrando su irracionalidad desde la vida negada de la víctima. (pp. 521-523)

El teórico del neoliberalismo Friedrich von Hayek lo ilustra muy bien: Una sociedad libre requiere de ciertas reglas morales que en última instancia se reducen a la mantención de vidas: no a la mantención de todas las vidas porque podría ser necesario sacrificar vidas individuales para preservar un mayor número de otras vidas. Por lo tanto las únicas reglas morales son las que llevan al "cálculo de vidas": la propiedad y el contrato. (citado por Hinkelammert, 2000, p. 85)

Esa lógica sacrificial y violenta permeó las diferentes estructuras sociales y se aprovechó del conflicto armado. Pero el "problema" no solo no se ha resuelto, sino que se ha agudizado a partir de dos factores fundamentales: a) el incremento y los nuevos rostros del conflicto armado y b) la presencia de megaproyectos económicos en algunas regiones, ligados a la implementación de un modelo económico neoliberal que nuevamente se afianza en el principio señalado como sacrificial y violento. Aunque el desarrollo del conflicto armado va mutando y tomando nuevas formas de victimización, y haya algunas diferencias, pues va a estar caracterizado por una mayor diversificación de los actores en conflicto y surgen otros intereses económicos ligados al narcotráfico y a los megaproyectos 
económicos, además de la consabida lucha por la posesión de la tierra, se mantiene dicho principio y, aún más, se incrementa.

En conclusión, la victimización de la población civil afecta ciertos sectores de la sociedad de forma doble, pues genera condiciones de empobrecimiento y condiciones de indignidad, pero, paradójicamente, no toca los resultados generales de la macroeconomía del país. Lo señalado también se puede ver en la llegada e intervención en territorios de comunidades indígenas y campesinas de proyectos económicos transnacionales, los cuales se dan a lo largo y ancho de la geografía nacional: comunidades afrocolombianas en el Chocó, pueblos u’wa, páez, nasa, embera-katío, los pescadores del río Sinú, los campesinos del macizo colombiano y los grandes megaproyectos petroleros de la Orinoquía. Estos son algunos de los casos en los que, en nombre del "desarrollo" y unidos al conflicto, se victimizaron y desconocieron los derechos fundamentales de las comunidades. Al respecto, se plantea:

Este desconocimiento ha generado escenarios de conflicto y violencia que se manifiestan, no solo en la aparición de grupos armados que imponen con la irracionalidad de las armas lo que con la razón y la argumentación no consiguen; sino también, con el desconocimiento de los valores tradicionales, del territorio y de la importancia de este en la constitución del Ser, en la construcción de las diferentes formas sustentables de relacionarse, de ver y entender el mundo. (Vélez, 2005, p. 4)

Se puede concluir, en este punto, que, aunque ha habido una mezcla de causas e intereses en medio del conflicto, que incluye pretensiones económicas de grupos de poder nacionales como internacionales que lo han agudizado, hay un factor de victimización de la población civil que lo atraviesa y que ha dejado una gran cantidad de víctimas asesinadas, así como una parte de la población rural sin tierra y desplazada que termina engrosando los cinturones de miseria de las principales ciudades del país. Este aspecto de la confrontación armada se sustenta en un principio de sacrificialidad, pues se afianza en la "necesidad de victimizar" a expensas de los "intereses mayores" y en la lógica de mantener una "salida" violenta las contradicciones propias de una sociedad. En este sentido, Ayala (2011), al referirse al conflicto en Colombia, expresa:

Indígenas, campesinos, afrodescendientes, así como sindicalistas o simples ciudadanos indiferentes a relaciones y a esquemas de poder político y a las circunstancias societales generadas por el conflicto armado interno, motivaron las acciones genocidas de los paramilitares en la medida en que estos representan intereses comunitarios y porque políticamente se opusieron al régimen político imperante y de forma 
original, al poder intimidatorio del grupo armado que los señaló como sus víctimas. (p. 57)

La consecuencia de esta doble victimización es la condición de pobreza por la que hoy muchos de los colombianos no pueden vivir una vida digna, con las condiciones básicas satisfechas y el respeto de sus derechos fundamentales, a esto le llamamos pobreza y es una forma de violencia.

\section{Hacia una relectura del texto de Jn 12}

A continuación, se reproduce el texto del cuarto Evangelio:

(1) Seis días antes de la Pascua llegó Jesús a Betania, donde vivía Lázaro, a quien Jesús había resucitado (ท̋ $\gamma \varepsilon ı \varepsilon v)$

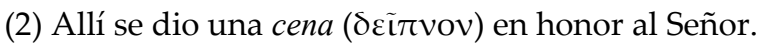

Marta servía, y Lázaro era uno que estaba a la mesa con él.

(3) María tomó entonces como medio litro de nardo puro, que era un perfume ( $\mu$ @oov) muy caro, y lo derramó sobre los pies de Jesús secándoselos luego con sus cabellos. y la casa (oỉkí $\alpha$ ) se llenó de la fragancia del perfume

(4-6) Judas Iscariote, que era uno de sus discípulos y que más tarde lo traicionaría, objetó: ¿Por qué no se vendió este perfume, que vale muchísimo dinero, para dárselo a los pobres ( $\pi \tau \omega \chi 0 \tilde{\mathrm{c} \varsigma})$ ?

Dijo esto, no porque se interesara por los pobres sino porque era

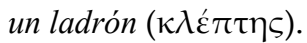

Y, como tenía a su cargo la bolsa del dinero ( $\gamma \lambda \omega \sigma \sigma o ́ \kappa о \mu о \nu)$, acostumbraba robarse ( $\dot{\beta} \beta \alpha ́ \sigma \tau \alpha \zeta \varepsilon v)$ lo que echaban en ella.

(7-8) Déjala en paz, respondió Jesús. Ella ha estado guardando este per-

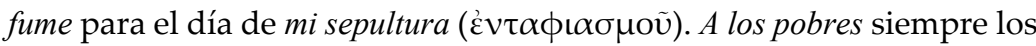

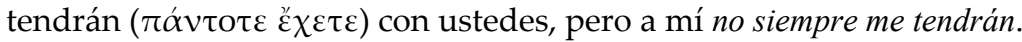
(9-11) Mientras tanto, muchos de los judíos se enteraron de que Jesús estaba allí,

y fueron a ver no solo a Jesús sino también a Lázaro, a quien Jesús había resucitado.

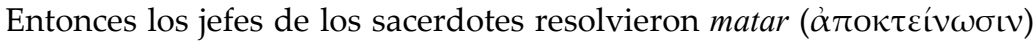
también a Lázaro, 


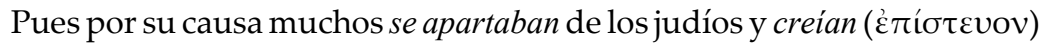
en Jesús. (Jn 12, 1-11)

Las expresiones señaladas en el texto se pueden organizar en dos campos o líneas de sentido (isotopías) (tabla 1).

Tabla 1. Expresiones en Jn 12

\begin{tabular}{|l|l|}
\hline Expresiones que afirman la vida & Expresiones que niegan la vida \\
\hline Resurrección de Lázaro (afirmación de la vida). & Ser un ladrón (atentar contra la vida, Jn 10, 10). \\
\hline $\begin{array}{l}\text { Compartir la cena en casa (construcción de la } \\
\text { comunidad de discípulos). }\end{array}$ & $\begin{array}{l}\text { Robarse el dinero de la bolsa común (destrucción } \\
\text { de la comunidad). }\end{array}$ \\
\hline Derramar el perfume (preparar). & El día de la sepultura (intento de frustrar la vida). \\
\hline Secar los pies (muestra de solidaridad-amor). & $\begin{array}{l}\text { Tener siempre pobres con ellos (para mostrar la } \\
\text { solidaridad y el amor). }\end{array}$ \\
\hline $\begin{array}{l}\text { Se llenó la casa de fragancia (la comunidad se } \\
\text { contagia del gesto hecho con Jesús). }\end{array}$ & $\begin{array}{l}\text { No tener siempre a Jesús entre ellos (preparar la } \\
\text { comunidad para su ausencia). }\end{array}$ \\
\hline $\begin{array}{l}\text { Se apartaban y creían (abrazaban una nueva } \\
\text { causa). }\end{array}$ & Matar también a Lázaro (persistía en su causa). \\
\hline La intención de dar dinero a los pobres. & \\
\hline
\end{tabular}

Fuente: Elaboración propia.

Poder plantear la expresión sobre los pobres en medio de la historia en casa de Lázaro nos permite ver que en el contexto que la envuelve se contrastan dos perspectivas: una que afianza la vida y la otra que propone la muerte. La comunidad de discípulos, simbolizada por la casa de la familia de Lázaro, se ve confrontada con una realidad: la inminente amenaza a la vida, no solo de Jesús, sino de ellos mismos. Judas Iscariote es quien representa una visión contradictoria dentro de la comunidad, pues se presenta como un "ladrón", quien engaña y roba la bolsa común, que nos lleva a la imagen de Jn 10, 10: “el ladrón no viene sino para robar, matar (sacrificar) y destruir (arruinar)". La tríada de acciones del ladrón son significativas en un contexto que atenta contra la vida de la comunidad y de los seres humanos en general. Son la forma en que se comporta un entorno hostil, un sistema en el que impera el lucro por encima de las personas, se atenta contra la vida y se sacrifican las vidas para sostener dicho sistema y finalmente se termina destruyendo y arruinando el ambiente vital, el ecosistema y el hábitat mismo. Tal actitud es la que toman los dirigentes judíos, que deciden matar a Jesús y a Lázaro, por su influencia en el ámbito de la comunidad judía más amplia. 
En medio de esta confrontación, aparece el gesto de María, la hermana de Lázaro, con el cual anticipa la situación que viviría Jesús en manos de los judíos, el apresamiento, el juicio y, luego, la muerte. Jesús mismo va a ser víctima del sistema de muerte, que en últimas es el mismo que ha llevado a la comunidad a la pobreza y exclusión, por esa razón los seguirán teniendo en medio de ellos. La comunidad de Jesús no solo se identifica con los pobres sino que los incorpora a ella, y entra en confrontación con las autoridades judías, y por tanto deben estar juntos para seguir resistiendo al sistema de muerte. Por ejemplo, más adelante en el relato, Jesús entra en Jerusalén en un pollino, gesto de identificación con la población empobrecida, la cual sale con palmas a recibirlo, en contraste con la actitud de la clase dirigente que pretende matar a Jesús. Esto nos deja ver que la opción por los pobres en la comunidad de Jesús implicó una confrontación con el sistema que empobrece y una ubicación desde el lugar del pobre como punto de partida para el seguimiento a Jesús (Jn 12, 12-15).

El planteamiento de Jesús no es necesariamente dicotómico, como regularmente se ha interpretado: no se trata de desatender a los pobres para ahora atenderlo a él, que es en ese momento la preocupación de María. Si los pobres son parte de la comunidad y la comunidad se ubica en su lugar, Jesús es también pobre, no solo en el sentido económico, sino porque se constituye en una víctima despojada de su vida y su materialidad por las autoridades judías y en últimas por el sistema hegemónico sacerdotal. Jesús empieza a vivir una persecución por parte de estas autoridades; según el texto juanino, la intención de matar a Jesús es permanente casi desde el inicio de su ministerio; la casa de Lázaro y María es un refugio, un ámbito de seguridad y solidaridad, allí es "ungido" y animado para continuar su viaje a Jerusalén donde se espera lo peor y donde no saldrá bien librado. La comunidad lo sabe, María lo sabe y se desborda en su amor por el Maestro, por el hombre que en su corporalidad manifiesta la necesidad del hermano. El gesto de María es profundamente amoroso, por no decir erótico, y permea toda la casa, toda la comunidad. Este desborde de amor es, pues, sancionado por Judas, así como se sanciona toda opción de amor por el pobre, cuando se solidariza con su realidad en forma integral. Pareciera que el pobre, en esta mentalidad de Judas, solo merece las "migajas"; lo que se pueda obtener de la venta del costoso perfume de nardo seguramente queda escaso frente a la realidad de la comunidad empobrecida. No se debe entonces plantear una dualidad entre el gesto de amor de María y la opción por los pobres, sino que hay que buscar la confluencia de los dos gestos en el contexto de la comunidad.

Hay una cuestión irónica en el texto que debemos captar bien. Se nos deja saber que la intención de Judas es hipócrita, por un lado, porque él 
mismo traiciona lo que dice, pues su ética es reprobable, pues "roba" a la comunidad, de lo que es para los pobres; pero, por otro, porque falsea la solución frente a la pobreza, vender el perfume y repartirlo no soluciona sino parcialmente la situación de la comunidad, la cual esperaría mucho más que eso, una transformación total de su condición de pobreza, una "vida en abundancia", según lo propone Jesús (Jn 10, 10). La antítesis de Jesús, según la comunidad de Juan, frente a la pobreza no es, pues, el mero asistencialismo, aunque este fuera a veces necesario y deseable, sino que es la vida vivida con dignidad, con plenitud, es decir, una vida digna de ser vivida, que implicaría la transformación de las condiciones que generan la pobreza. Es como el gesto de María, algo extremo que sobrepasa lo acostumbrado, que revuelca lo sistémico, que promueve un caos en medio de un orden asfixiante y cómodo. La cuestión frente al pobre implicaría en consecuencia "derramar el perfume" sobre la víctima para que su aroma permee toda la casa, todo el sistema.

Hay una dicotomía más que se hace, con frecuencia, al interpretar el texto: se separa lo individual de lo colectivo, como si Jesús se pusiera en lugar de la comunidad y entrara en competencia con ella. Como ya se ha dicho, en el texto Jesús es también pobre, víctima, y su necesidad personal y particular es parte de la necesidad de la comunidad, resolver su propia necesidad es también resolver la de la comunidad. No se puede por ende colectivizar la pobreza, perder el rostro particular del pobre, puesto que las generalizaciones terminan justificando las desigualdades. Cuando hay solidaridad con el ser humano concreto, hay solidaridad con la humanidad. Hace daño ver a los pobres como masa social, como una mera colectividad, y no entender que hay diferencias en esa colectividad, que no es lo mismo si se trata de una mujer, de un niño, de un afro o de un indígena, pues cada uno vive esa condición a su manera y requiere una solución a su manera, no impuesta desde afuera.

La urgencia de solidaridad con Jesús, para María, no la coloca de espaldas ante la comunidad como colectivo. En la narración de Mateo, esto parece estar menos claro para la incipiente comunidad de discípulos quienes se enojan con la mujer al derramar el perfume. Aquí la crítica se dirige a la comunidad que no entiende el gesto de la mujer con Jesús. La comunidad debe aprender a reconocer el rostro de la mujer, pues en el relato no se conoce su nombre, pero la comunidad hará memoria de ella al predicar el Evangelio de Jesús; ella aquí es el pobre que irrumpe en la comunidad, que está ahora en medio de ellos, y la comunidad aprenderá a reconocerla como parte valiosa, como testigo del Evangelio. 
La trilogía de acciones emprendidas por el "ladrón” de Jn 10, 10, representados por Judas en la escena del capítulo 12, son contrarrestadas por la acción de "traer vida" y una "vida en abundancia" por parte de Jesús, no en términos mercantilistas o egoístas, sino en sentido, propósito y dignidad. Pero también por la acción de María de ungir a Jesús, mostrando su solidaridad y afecto por él, acosado por el sistema que terminará victimizándolo, un amor que sobrepasa los cálculos medio-fin, utilitaristas, y se desborda al dar, dando lo mejor para el otro. Finalmente, a la acción de Marta y Lázaro de abrir su casa, no solo a Jesús, sino a los pobres, para construir comunidad y convocar en torno a la propuesta de Jesús a otros, aun aquellos que estaban inmersos en la dinámica misma del sistema de muerte, y así se convierten en testigos de Jesús y apuestan por una vida con dignidad. Estas trilogías se oponen así (figura 1):

Figura 1. Contraposición de las trilogías.

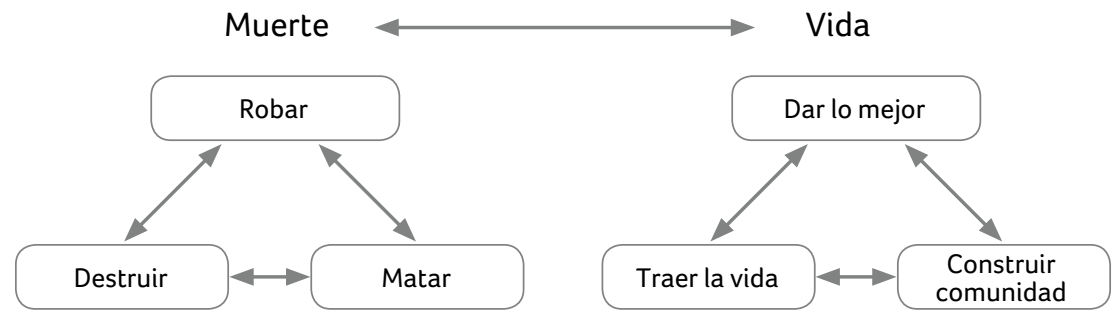

Fuente: Elaboración propia.

La propuesta, inicialmente planteada, de entender la pobreza como una forma de violencia y como una consecuencia de otras formas de violencias, como en el caso colombiano de la violencia armada y en general en América Latina de la violencia estructural, da una visión diferente para entender el texto que nos ocupa y especialmente la expresión central sobre los pobres. La preocupación "postergada" de Jesús por los pobres se antepone a la pretensión inmediatista de Judas, que obedece, no a una pretensión genuina por su situación de pobreza, sino por las utilidades que dicha preocupación puede dejarle. Es una posición utilitarista, insensible y violenta que representa Judas, pero que el Evangelio de Juan nos deja ver que pertenece a un grupo más amplio, que refleja una realidad más sistémica, que tiene el poder religioso y económico y que atenta contra la vida de Jesús y sus discípulos. La pobreza, en esta perspectiva, es, pues, una forma de violencia y a la vez es consecuencia de otras formas de violencia, el pobre es, por ende, víctima de esta violencia y queda expuesto a otras violencias. 
¿Qué podemos hacer o continuar haciendo? ¿Cómo hacerlo? ¿Cómo nos desafía esta relectura a la Iglesia y a la teología en América Latina heredera de la opción por los pobres?

\section{Implicaciones para un trabajo ecuménico desde la "opción por los pobres"}

La visión antes expuesta, desde el acercamiento categorial y la relectura del texto bíblico, en la que consideramos una perspectiva de la pobreza como una forma de violencia y en relación con otras violencias, nos coloca en una perspectiva más amplia a la hora de pensar la acción de la Iglesia frente a la pobreza. Pues no se trata de superar la indiferencia con acciones asistencialistas para paliar la realidad de pobreza y sus consecuencias sociales, sino de empezar por preguntarnos también nuestro grado de responsabilidad en la permanencia y ampliación de la pobreza en nuestros contextos locales, nacionales y continentales. Se trata de pensar hasta qué punto nuestro discurso teológico y acciones sociales han generado y acompañado procesos concretos para la transformación de realidad de pobreza y marginalización social.

Debemos evitar dos tipos de lectura del texto y la realidad que nos han perjudicado en nuestro compromiso teológico y eclesial: el primero de ellos es la lectura literalista, en la que las expresiones bíblicas se interpretan al margen de su contexto social y cultural; el segundo sería una lectura que, si bien tiene en mente el contexto del texto, no lo conecta en forma contundente con el contexto actual, y señalo contundente porque no se trata de una conexión conceptual y meramente teórica, sino concreta, desafiante, que se vuelca a una práctica transformadora, política si se quiere, a partir del texto. Mucho de lo que planteamos desde una lectura contextual y sociológica de la Biblia se queda a veces en discurso y poco genera procesos reales de transformación social.

De Wit (2015), al revisar la relación entre la lectura de la Biblia y el anhelo de transformación social que de ella se pueda desprender en el contexto de la lectura popular de la Biblia en América Latina, así como en la experiencia de los grupos de estudios bíblicos en Europa, plantea un vacío que percibe en estos procesos. En primer lugar, estos relatos sobre el impacto de la lectura de la Biblia en las personas no pueden ser ignorados, iporque de hecho sucede algo cuando las personas leen la Biblia! En segundo lugar, la trayectoria de esta transformación supuesta o esperada rara vez es seguida; si alguna vez se sigue, no se aclara en 
qué consiste, no se explica cómo se produce esta transformación. En otras palabras, rara vez recibimos una respuesta clara sobre qué elementos en la interacción entre los textos de la Biblia y los lectores cambia esta interacción en un guion para la acción transformadora (p. 57).

Si se presta atención a este llamado de De Wit (2015), implicaría prestar más atención a los procesos en los cuales la lectura contextual de la Biblia ha generado o acompañado procesos de transformación social. Se ha logrado la superación de dichas condiciones y realidades, a diferentes niveles, en el barrio, en el municipio o en el país. Claro que esos procesos existen, pero no los hemos documentado y acompañado lo suficiente desde la institucionalidad eclesial. Algunos seguramente resisten a pesar del aislamiento territorial y nos muestran el valor de la esperanza en medio de condiciones desesperanzadoras; son como la casa de Lázaro, Marta y María, comunidades de esperanza en las que el perfume se derrama y permea con su fragante olor de amor a toda la comunidad alrededor.

Se podrían mencionar algunos ejemplos, algunos que conozco personalmente y otros por intermedio de amigos. La comunidad en Macayepo, principalmente de confesión adventista, quienes retornan a su pueblo del cual fueron expulsados por el conflicto armado después de varios años; los grupos de Casitas Bíblicas en Bogotá, de confesión católica pero vinculados a procesos ecuménicos, en el barrio Diana Turbay y vecindades; la Casa Construyendo Sorodidades en el barrio El Jordán en Cali, que ha trabajado empoderando mujeres del sector a partir de una relectura permanente del texto bíblico; la comunidad en Las Pavas, de confesión evangélica, quienes se han resistido desde su fe a ser desalojados de su territorio por proyectos económicos latifundistas en la región; $\mathrm{y}$, finalmente, la comunidad de paz de Apartadó, quienes desde la no violencia inspirada en el modelo de Jesús persisten en un modelo comunitario de resistencia frente a diferentes actores armados y políticos. La cuestión es qué tanto de eso valoramos, conocemos y hemos sistematizado para conocer sus aportes, estrategias, luchas $\mathrm{y}$, principalmente, su testimonio de fe.

Algunas de estas experiencias son de carácter ecuménico o están abiertas al trabajo ecuménico, pues lo que nos cuesta más dificultad a nivel institucional en las comunidades se va dando en forma más profunda, pues la realidad de victimización y la lucha que se desprende por la vida con dignidad va generando lazos comunitarios que luego son alimentados por la lectura del texto bíblico, algo también para conocer más y profundizarlo. Estas experiencias plantean la necesidad de fortalecer la construcción de comunidades de fe en torno a la reflexión del Evangelio de Jesús, en una perspectiva de transformación de sus realidades particulares desde el "dar lo mejor" y el "traer vida” como apuestas antagónicas a las 
acciones de "robar, matar y destruir" partiendo del entorno que los rodea. ¿Cómo podemos ayudar, desde la reflexión y construcción teológica, a estas comunidades de fe? ¿Cuáles son los compromisos concretos que desde las Iglesias, ONG e instituciones de educación vinculadas a las Iglesias nos llevan a acompañar, respaldar e involucrarnos en sus procesos? Si se me permite la metáfora: “debemos derramar el perfume sobre sus pies trajinados". Partiendo de la propuesta desarrollada desde la relectura del texto juanino, se pueden vislumbrar tres ámbitos en y desde los cuales la teología puede contribuir al desafío planteado.

El primero tendría que ver con la construcción de comunidad, ${ }^{4}$ una teología que ayude en estos procesos, que retome la experiencias de comunidades de base, tanto católicas como protestantes, que desarrolle una eclesiología que genere alternativa frente a nuevas formas eclesiales mercantilistas y evasivas frente a la realidad de pobreza y violencia, que proponga temáticas, materiales, acompañamiento a estas comunidades en el campo como en la ciudad, desde una perspectiva ecuménica y comprometida; Colombia no necesita más Iglesias, requiere más comunidades.

El segundo debe apuntar a una nueva diaconía, al estilo del dar lo mejor de María, una teología que desarrolló nuevas formas de misión entre las comunidades más atropelladas por los sistemas y las prácticas de muerte, que acompañe proyectos de servicio, de generación de trabajo, que canalice la ayuda más desde la participación de la comunidad y no tan solo desde la institución y cree dependencias del asistencialismo sin formación y organización de las comunidades.

En tercer lugar, pero sin ánimo de agotar la discusión, sería trabajar en el ámbito del dar vida, conforme a la propuesta de Jesús, encarnando su legado. Se podría llamar una bioteología, que se preocupe por los diferentes ámbitos desde los cuales se atenta contra la vida con dignidad de las comunidades y de los movimientos sociales. Se necesita aquí relacionar, por ejemplo, desde la reflexión teológica y sociológica, las acciones de corrupción y violencia en nuestro país. Tenemos la idea de que ya la lucha en contra de la violencia da su paso ahora a la lucha en contra de la corrupción, pero la corrupción ha ido de la mano de la violencia en nuestro país; las políticas públicas deficientes y corruptas han permitido

4 El sugestivo estudio de Torres (2013) resalta el nuevo interés de la categoría “comunidad" en las ciencias sociales hoy, y frente a concepciones facilistas de su uso propone que "se hace necesario definir una perspectiva que reivindique el potencial impugnador, instituyente y emancipador que le atribuyen algunos pensadores a la comunidad y que reivindican los movimientos de los pueblos originarios de América; a la vez, que tome distancia con toda visión esencialista, unitarista y homogeneizadora de comunidad" (p. 219). 
el amparo de los que han usado, y siguen usando, la violencia como una forma de imponer sus proyectos económicos y políticos en medio de comunidades campesinas, afro e indígenas.

\section{Conclusión}

Hay que confesar que se dejan más preguntas que respuestas en esta reflexión, desafíos más que recetas, pues estas respuestas se deben construir más en el terreno que en el papel. Sin embargo, se ha intentado, a partir de una relectura del texto que provocaron estas líneas, plantear la necesidad de deconstruir perspectivas que no permiten dar pasos hacia acciones transformadoras de realidades de pobreza. El resultado de dicha relectura se acompaña de una relectura de la misma realidad, propone entender la pobreza como una forma de violencia y el resultado de otras violencias, y desde esta posición comprender la expresión de Jesús, no como una resignación ante la presencia eterna de los pobres o una justificación de su existencia, sino precisamente a su rechazo, como forma de expresión de acciones de muerte. La mirada de la pobreza como una forma de violencia ayuda a conectar entonces el contexto y la realidad de pobreza con una relectura del texto bíblico. En ambos lados, encontramos que esta categoría doble, pobreza-violencia, permite en consecuencia replantear una interpretación del texto bíblico tratando de justificar la existencia de la pobreza-violencia, a no ser que nos coloquemos en el lado de quienes proponen un sistema de muerte, a no ser que justifiquemos también las acciones del "ladrón", robar, matar y destruir, y abandonemos el llamado de Jesús a traer vida, y vida con dignidad.

Los desafíos que nos deja esta perspectiva para la tarea teológica y eclesial, asumida desde una perspectiva ecuménica, se enmarcaron en tres tareas: a) una eclesiología que acompañe la construcción de comunidad, b) una diaconía más allá del asistencialismo o dependencia de las comunidades y c) una bioteología que afronte las diferentes formas de unión entre la violencia y la pobreza, que promueva desde la comunidades acciones a favor de la vida, que siga denunciando las acciones de muerte y despojo a las cuales son sometidas nuestras comunidades más vulnerables y vulneradas, que asuma la solidaridad en los contextos en los que las nuevas formas de violencia desaparecen a nuestros líderes sociales y comunitarios. No puede ser que el "ladrón" pueda seguir operando como si no pasara nada. Repensar la opción por los pobres implicaría por tanto asumir el desafío de la pobreza como violencia y las violencias como causantes de la pobreza. 


\section{Referencias}

Arboleda, S. (2017, mayo 28). Buenaventura: exclusión histórica y represión estatal. Razón Pública. Recuperado de https://www.razonpublica.com/index.php/ regiones-temas-31/10283-buenaventura-exclusi\%C3\%B3n-hist\%C3\%B3rica-yrepresi $\% \mathrm{C} 3 \% \mathrm{~B} 3 \mathrm{n}$-estatal.html

Ayala Osorio, G. (2011). Paramilitarismo en Colombia: más allá de un fenómeno de violencia política. Cali, Colombia: Universidad Autónoma de Occidente.

Consejo Episcopal Latinoamericano. (1989). Medellín conclusiones: la Iglesia en la actual transformación de América Latina a la luz del Concilio. Bogotá, Colombia: Autor.

De Wit, H. (2015). Bible and transformation: The many faces of transformation. En H. de Wit \& J. Dyk (Eds.), Bible and transformation: The promise of intercultural Bible reading. (pp. 53-74). Atlanta, EE. UU.: Society of Biblical Literature.

Dussel, E. (1998). Ética de la liberación en la edad de la globalización y de la exclusión. Madrid, España: Trotta.

Hinkelammert, F. (2000). Crítica a la razón utópica. San José, Costa Rica: DEI.

Hinkelammert, F. (2011). Fenomenología de la liberación. Recuperado de http:// www.pensamientocritico.info/index.php/articulos-1/franz-hinkelammert1/ fenomenologia-de-la-liberacion

Mondragón, H. (2003, enero 1). ¿Por qué la guerra y por qué la resistencia no violenta en Colombia? Recuperado de https://zcomm.org/znetarticle/por-que-la-guerra-ypor-que-la-resistencia-noviolenta-en-colombia-by-hector-mondragon/

Núñez, J. y Ramírez, J. C. (2002). Determinantes de la pobreza en Colombia: años recientes. Bogotá, Colombia: Naciones Unidas. Recuperado de https://repositorio.cepal. org/bitstream/handle/11362/4789/1/S029701_es.pdf

Palabras del Presidente Juan Manuel Santos en el foro del Consejo Mundial de Iglesias (2018, febrero 28). Recuperado de http://es.presidencia.gov.co/discursos/180228Palabras-del-Presidente-Juan-Manuel-Santos-en-el-foro-del-Consejo-Mundialde-Iglesias

Pixley, J. y Boff, C. (1986). Opción por los pobres. Madrid, España: Paulinas.

Quijano, A. (2000). Colonialidad del poder y clasificación social. Journal of World-Systems Research, 6(2), 342-386. DOI: https://doi.org/10.5195/jwsr.2000.228

Torres Carrillo, A. (2013). El retorno a la comunidad: problemas, debates y desafíos de vivir juntos. Bogotá, Colombia: Fundación Centro Internacional de Educación y Desarrollo.

Velásquez Forero, A. (2014). La globalización neoliberal y su impacto en el proceso de reconfiguración del sistema capitalista colombiano en los albores de la sociedad del siglo XXI (1990-2010) (Tesis de doctorado). Universidad Nacional de Costa Rica, Heredia, Costa Rica. 
Vélez, I. (2005, septiembre). Las multinacionales y los megaproyectos en Colombia. Recuperado de https://www.ecoportal.net/temas-especiales/desarrollo-sustentable/ las_multinacionales_y_megaproyectos_en_colombia/

Verdad Abierta. (2011, septiembre 11). Palma y los paramilitares en Chocó. Recuperado de https://verdadabierta.com/la-palma-y-los-paramilitares-en-choco/

Villatoro, P. (Comp.). (2017). Indicadores no monetarios de pobreza: avances y desafíos para su medición. Santiago de Chile, Chile: Naciones Unidas. 